\title{
BokSmart: Safe and effective techniques in rugby union
}

\author{
Michael Posthumus (BSc(Med)(Hon) Exercise Science) $)^{1}$ \\ Wayne Viljoen (PhD) ${ }^{2}$ \\ ${ }^{1}$ UCT/MRC Research Unit for Exercise Science and Sports Medicine Department of Human Biology, University of Cape Town \\ ${ }^{2}$ Manager: BokSmart National Rugby Safety Programme
}

\begin{abstract}
As with any contact sport, rugby union has a high risk of injury. The majority of injuries result from contact phases of play such as the tackle, taking the ball into contact, the scrum, the lineout and the ruck and maul. Many techniques associated with a reduced risk of injury can be taught. The need for coaches to emphasise correct technique is extremely important and one of the few possible modes to reduce injuries, particularly non-fatal catastrophic injuries to the head, neck, brain and spine. This paper provides evidence of safe techniques during the contact phases of the game (tackling, taking the ball into contact, scrum setting and engagement, lineouts as well as rucks and mauls). Examples are also given to show that safe techniques often are the most effective techniques from a performance perspective.
\end{abstract}

\section{Introduction}

Rugby union is played in more than 100 countries across 5 continents by more than 3 million people between the age of 6 and $60{ }^{14,15}$ In South Africa, a reported total of 326565 rugby players are currently participating in club and school rugby matches. ${ }^{38}$ As with any contact sport, rugby union has a high risk of injury. The incidence of match-related injuries is much higher than in other popular South African team sports. A total of 218 and 120 'time-loss' injuries per 1000 hours of player exposure during matches have been reported for international and club rugby respectively. ${ }^{2}$ Soccer and cricket have a much lower incidence of injuries, with international and club soccer resulting in 42 and 26 injuries respectively per 1000 hours

\section{CORRESPONDENCE:}

Michael Posthumus

UCT/MRC Research Unit for Exercise Science and Sports Medicine

Department of Human Biology, University of Cape Town

Sport Science Institute of South Africa

Boundary Road

Newlands 7700

South Africa

Tel: 27-21-650-4572

Fax: 27-21-650-7530

E-mail: michael.posthumus@uct.ac.za of player exposure during matches and international and club cricket resulting in 2.8 and 1.8 injuries respectively per 1000 hours. $^{2}$

The majority of injuries result from contact phases of play such as the tackle, taking the ball into contact, the scrum, the ruck and maul and the lineout. ${ }^{1,6}$ Although the tackle situation has demonstrated the majority of injuries in South African schoolboy $(55 \%)^{33}$ and senior rugby players $(40 \%))^{3}$ the scrum carries a $60 \%$ greater risk per event. ${ }^{6}$ Injuries to the head and neck resulting in permanent (>12 months) severe functional disability, which have recently been defined as 'non-fatal catastrophic injuries ${ }^{, 6}$ are unfortunately also a part of the game. ${ }^{25}$ Head and non-fatal catastrophic neck injuries have been shown to range from $12 \%$ to $33 \%$ of all injuries. ${ }^{1}$ A 2001 analysis ${ }^{30}$ of published cervical spine injury data reported distributions of catastrophic cervical spine injuries in specific phases of play. The scrum resulted in $40 \%$, the tackle resulted in $36 \%$, the ruck and maul in $17 \%$ and other phases only resulted in $6 \%$ of catastrophic cervical spine injuries.

During recent years the incidence of head and cervical spine injuries has caused huge concern to the medical fraternity. $12,18-$ 20,25,30,31,36,40 Measures to reduce the number of catastrophic injuries have included law changes and educational initiatives. ${ }^{25,30,31}$ Laws governing the scrum, including scrum engagements, and the tackle have been adapted to make the game safer and to avoid non-fatal catastrophic injuries to the cervical spine. ${ }^{16,25,30}$ Examples of rule changes introduced to reduce the incidence of catastrophic injuries include the crouch-touch-pause-engage sequence of scrum engagement and the outlawing of the high and spear tackles. A recent evaluation ${ }^{31}$ of a national injury prevention programme (the New Zealand RugbySmart programme) in rugby union showed that its introduction has coincided with a reduction in the rate of disabling spinal injuries. Since the introduction of the programme in 2001 the incidence of scrum-related spinal injuries decreased from the predicted number (based on the injury rates of previous periods) of 19 to 8 . Similarly, injuries resulting from tackles, rucks and mauls decreased from the predicted number of 9 to 7 . This study demonstrates the benefit of teaching safe and effective techniques in rugby.

The need for coaches to emphasise correct technique is extremely important and one of the few possible modes to reduce injuries, especially non-fatal catastrophic injuries to the head, neck, brain and spine. The purpose of this paper is not only to provide evidence of safe techniques during the contact phases of the game (tackling, taking ball into contact, scrum setting and engagement, lineouts as well as rucks and mauls), but also to provide empirical evidence that safe technique is effective technique. Coaches are thus able to ensure greatest safety to their players while improving their technical effectiveness. 


\section{Tackling}

In studies reporting the incidence of rugby union injuries, tackling has been shown to be the cause of $25 \%$ and $14 \%$ of injuries in schoolboy and adult South African rugby players respectively. ${ }^{3,33}$ The most frequent body sites injured during tackling (injuries to the tackler) were the upper limb (35\%), including the shoulder and clavicle; the head, neck and face (28\%); and the lower limb $(27 \%) .{ }^{41}$ It has been reported that the injury with the highest incidence in tackling is a cervical nerve root injury for forwards and concussion for backline professional rugby players. ${ }^{1}$ These results are in agreement with previously reported injuries in South African schoolboys, which similarly demonstrated a large proportion of tackle injuries to the head and neck. ${ }^{33}$ Roux et al. ${ }^{33}$ also reported concussion to account for $14 \%$ of injuries incurred while tackling. Tackle injuries were most often associated with front-on tackling, rather than tackling from the side or from behind. 32,41

The tackle has been shown to be the major contributor to serious catastrophic cervical spine injuries (36\% of all reported non-fatal catastrophic cervical injuries). ${ }^{30}$ Trauma to the cervical spine may occur during tackling through vertex impacts and hyperflexion. ${ }^{25} \mathrm{Al}-$ though the mechanism of cervical spine tackle injuries has not been substantially reported in rugby union, it has been proposed to be a result of hyperflexion of the neck. ${ }^{25,30}$ The mechanism of catastrophic cervical spine injuries as a result of tackling in American football has however been very well researched and documented. ${ }^{12}$ Axial loading which occurs during contact with the top or crown of the head or helmet (referred to as spear tackling in American football) is the primary mechanism of catastrophic spinal injuries in American football. $^{12}$

Non-fatal catastrophic cervical spine injuries, which occur during tackling caused by both mechanisms described above, are avoidable through coaching and implementing safe and effective technique. A general lack of skill from the tackler has been highlighted as a risk factor to catastrophic cervical injuries and concussion, $9,25,30$ and as the primary reason for a much higher rate of tackling injuries sustained among schoolboys. ${ }^{3}$ It is therefore important, especially at lower levels, to emphasise the basics of safe and effective tackling technique. Primary emphasis should be placed on the head and neck position in the tackle. Most importantly, players should be coached to place their heads in the safest area when tackling, e.g. placing the head behind the buttocks of the ball carrier, and to ensure that the face is always up when performing a side-on tackle.

The cervical spine is able to dissipate forces by controlled spinal motion through the paravertebral muscles, eccentric contractions and intervertebral discs. ${ }^{39}$ When the natural lordosis (curve) of the cervical spine is lost, due to head-down contact, the forces generated by contact to the top of the head are transmitted along the vertical axis of the spine and can no longer be dissipated. ${ }^{12}$ It is under these conditions in which the spine fails in a flexion mode, resulting in fracture which may sever the spinal cord and cause instant paralysis. ${ }^{25}$ Forced hyperflexion from entering the tackle with the head flexed may also result in a similar vertebral dislocation or fracture and subsequent catastrophic cervical injury.
Ex vivo laboratory experiments of the cervical spine have presented evidence to suggest that the cervical spine is able to bear the greatest axial forces when in the natural lordotic position. ${ }^{26,27}$ Loss of lordosis has been shown to increase the risk of cervical spine injuries. $^{27}$ This principle also applies to the thoracic and lumbar vertebrae, when the flexed and twisted spine is less able to resist applied axial torques. Thus a loss of spinal lordosis may also increase the risk of torsional injury. ${ }^{21}$ Although the tackler's anatomical site of contact should always be the shoulder, safety must be ensured by keeping the face up and focussed on the core of the approaching ball-carrier. The spine should also always be in its strongest position of resisting front-on axial forces and sideways axial torques, and thus a tackle should always be performed with a neutral straight spine with natural lordosis (spine in line) with the tackler's shoulders above the hips. This position will not only reduce the risk of injury but also produce greater force development and thus improve the effectiveness of the tackle.

Contrary to what is often believed, approaching the tackle halfheartedly may in fact place the tackler at greater risk of injury. Greater differential impact between the tackler and the person being tackled seems to be a major risk factor for injury to the player with lower momentum. ${ }^{9}$ This emphasises the need to dominate the tackle situation, and it has been suggested that players gain momentum again as soon as possible after completing a phase of play in order to reduce the probability of being injured in the next tackle in which they are involved. ${ }^{9}$ Dominating the tackle situation requires the tackler to close down the space between himself and the attacking player while ensuring a powerful leg drive into the tackle. Shortening steps before contact, driving forcefully with the shoulder on the same side as the leading leg and hitting into the trunk is the safest and most effective way to execute a tackle.

Tackles from the front (front-on) have been shown to result in the greatest number of injuries and injury burden (days off) per 1000 player-hours. ${ }^{32}$ Although this finding is largely due to the high frequency of the front-on tackle, a focus on this specific event has the greatest potential to reduce morbidity of tackle injuries. ${ }^{8}$ Furthermore, the nature of the game makes this tackle unavoidable and thus it is important to coach safe and effective techniques. Previous research ${ }^{41}$ reporting injury frequency to the tackler has shown injury to be greater when tackling the trunk $(57 \%)$ than when tackling low (43\%), but this may also be explained by the higher frequency of the trunk tackle (130 tackles per match) compared with the low tackle (30 tackles per match). A recent study ${ }^{32}$ has found the injury rate and injury burden (days off) per 1000 player-hours to be lower when performing a tackle to the middle zone (trunk) of the ball-carrier, compared with tackling low (legs). When assessing the tackling mode of all recorded 'stopping' front-on tackles, which was the tackling mode presenting the greatest number of injuries to the tackler, reported in the study by Wilson et al., ${ }^{41} 64 \%$ of injuries occurred while tacking low (7 out of 11 ) and only $36 \%$ of injuries occurred while tackling the trunk (4 out of 11). An analysis of contact area playing styles has also observed that team success requires tackles to the waist, rather than leg tackles. ${ }^{16}$ It may therefore safely be recommended that the zone between the upper thigh and the sternum be the target for contact when performing a front-on tackle; this recommendation will ensure safe and effective technique. 
In a recent effort to further understand the relationship between tackle-related injuries and fatigue it was demonstrated that an effective tackling technique under non-fatigued conditions does not necessarily result in effective tackling technique when fatigued. ${ }^{8}$ This emphasises the importance of conditioning, and provides evidence for advocating the practice of safe and effective tackling technique training under fatigued conditions.

\section{Ball-carrying and taking the ball into contact}

Although most frequencies are similar, the bulk of the published literature has shown the incidence of injury to the ball-carrier as being greater than to the tackler. ${ }^{1,3,17,18,25,32,33}$ A recent comprehensive analysis of 52248 tackle events in 10050 player-hours has shown the burden (days off) of injury, which is a product of severity and rate of injury, to the ball-carrier to be nearly double the burden to the tackler. $^{32}$ Thus, it may be argued that coaching safe and effective ball-carrying and attacking techniques is more important than coaching correct tackle techniques.

Anatomical sites most often injured by the ball-carrier include the lower limb (51\%), the head, neck and face (17\%), and the upper limb $(15 \%) .{ }^{41}$ The majority of injuries were sprains/strains (43\%) and haematoma/bruises (29\%). It has been reported that the injury with the highest incidence to the ball-carrier is a thigh haematoma for both forward and backline rugby players. ${ }^{1}$ The injury resulting in most days absent in professional rugby players were anterior cruciate ligament and medial cruciate ligament injuries to the forwards and backs respectively. ${ }^{1}$ Non-fatal catastrophic cervical spine injuries have also been reported to occur to the ball-carrier, in similar frequencies to those of the tackler. ${ }^{25,30}$

Catastrophic cervical injuries to the ball-carrier are predominantly caused by illegal tackles. ${ }^{25,30}$ Both high tackles and spear tackles put the ball-carrier at a significant risk of cervical spine injury. Spear tackling, which in rugby union is described as lifting the ballcarrier off his feet and driving him head first into the ground, has been outlawed and stricter enforcing of this law has recently been introduced. ${ }^{15,25,30}$ The illegal high tackle is also outlawed due to its high risk. ${ }^{15,25}$ Tackles around the neck may force the neck into either hyperextension (bent backwards) or hyperflexion and rotation, which may be sufficient to cause fracture or dislocation of the cervical vertebrae and possibly severing of the spinal cord. Cervical injury due to axial loading (as described in the section on tackling) may also occur in the ball-carrier either from being spear-tackled or making direct contact with the top of the head by entering the tackle with the head down. ${ }^{25,30}$

The essential safe body posture of tackling also applies to safe technique when taking the ball into contact. When contact is unavoidable, the contact situation should always be entered with the head up and back straight. As explained in the section on tackling, loss of spinal lordosis has been shown to be a weaker position; greater force and torque may be transferred into the contact situation when a neutral back with natural lordosis is maintained. ${ }^{10,21,26,27}$

Effective and successful ball-carrying techniques have been well described. $^{22,35,37}$ Dominating contact, ${ }^{22,35}$ evading contact, ${ }^{35}$ body position in contact $^{22,37}$ and turning towards your support ${ }^{22,37}$ have all been shown to be associated with effective and successful ball-carry- ing. Sayers and Washington-King ${ }^{35}$ characterised effective ball-carries into contact, and showed that maximal running intensity, running at an oblique angle and performing a forward step, all resulted in the greatest number of positive outcomes while carrying the ball. Oblique evasive running (defined as running 'towards the defensive line, but not directly at defenders; e.g. where an attacker ran at the shoulder of a defender') measured much greater positive outcomes compared with running at a defender or angled running (defined as 'runs not directed towards the defensive line; e.g. where an attacker tries to run around the defence using speed'). ${ }^{35}$ Performing a forward step (defined as an 'evasive movement involving stepping motions originated from the outside leg and involving predominantly forwards motion'), displayed much greater positive outcomes than a lateral step (defined as an 'evasive movement involving predominantly sideways stepping motion') and a swerve (defined as an 'evasive movement initiated from the inside leg). ${ }^{35}$ Dominating the tackle situation is essential to crossing the advantage line. When the ball-carrier was able to meet the tackler once he had crossed the advantage line, the ball was retained $67 \%$ of the time, compared with a ball retention rate of $44 \%$ when the advantage line was not reached. ${ }^{22}$ As described for the tackler, the prevalence of injury is much greater to the player in the tackle situation with the lower momentum. ${ }^{9}$ Therefore, dominating the contact situation will once again emphasise the concept of safe technique also being the most effective technique.

Evasion techniques such as oblique running and forward stepping will reduce the magnitude of the collision forces, ${ }^{35}$ thereby decreasing the effectiveness of the tackle while making the ball-carry safer and very effective. Ball-carriers should not run directly at defenders - this will not only decrease the effectiveness of the ball-carry, ${ }^{35}$ but also place the ball-carrier and the tackler under unnecessary risk of injury.

A low body position by the ball-carrier and turning towards supporting players has also been shown to be associated with success in contact. $^{22,37}$ Ball retention was the highest when the body position in contact was classified as low (56\%), compared with a medium $(47 \%)$ and a high (32\%) body position, and when the ball-carrier turned his body towards his support (68\%), compared with away from his support $(62 \%)$ and not turning at all $(42 \%) .{ }^{22}$ A more recent analysis of the contact situation ${ }^{37}$ showed similar results. It was found that possession was retained $90 \%$ of the time when the ball was carried into contact with a low body position. A low body position is not only the most effective carrying position, but also the strongest and safest. A low body position will widen the base of support, lower the centre of gravity of the ball-carrier and allow for a more powerful leg drive into contact. Turning towards support in the tackle situation is a very significant action in retaining possession, ${ }^{22,37}$ but also protects the ball-carrier from injury caused by more defenders joining the tackle situation.

\section{Scrum setting and engagement}

When scrumming injuries are reported as the incidence of injury per player-hours, the high risk of the scrum situation is often underestimated, ${ }^{6}$ but when evaluating the propensity of a contact event to induce injury, the scrum is the contact phase bearing the greatest injury risk. ${ }^{6}$ Scrumming was shown to carry a $60 \%$ greater risk of injury than the tackle situation. ${ }^{6}$ It is furthermore worth noting that the vast 
majority (>80\%) of scrum injuries occur to the hooker and prop, ${ }^{25,33}$ therefore emphasising safe and effective technique in these positions is particularly important.

Injuries to the head and neck contribute to $42 \%$ of all schoolboy scrum injuries. ${ }^{33}$ Scrumming has also been shown to be the phase of play which induces the greatest number of catastrophic cervical spine injuries. ${ }^{30}$ Although comparative data have never been published, the risk of catastrophic cervical injuries per event for the hookers and props (front-row forwards) during scrumming would be considerably greater than any other position during any contact event. ${ }^{40}$

It has been shown that the impulsive impact force on a scrum engagement exceeds the threshold of injury to the spine. ${ }^{23}$ This emphasises firstly the importance of specific scrum technique training, which includes correct alignment of the head, neck and trunk, and adequate back, shoulder and neck strength to maintain a safe body position during engagement. ${ }^{23,36}$

More than $90 \%$ of scrum-related catastrophic cervical spine injuries occurred during either scrum engagement $(47 \%)$ or a collapsed scrum $(46 \%) .{ }^{30}$ The remainder of injuries were caused by front-row forwards actively extending their necks and driving the opposite front-row upwards; this has been termed 'popping', ${ }^{25}$ or more recently 'scrumming up'. This act places the opposition at great danger of catastrophic cervical injury, is highly illegal and should be strongly discouraged. $^{15}$

During scrum engagement vertex impacts caused by head down contact (similar to what was described in the section on tackling) has the potential of causing catastrophic cervical injuries. ${ }^{25,30}$ The crouch-touch-pause-engage sequence of scrum engagement was introduced to reduce the number of these injuries. ${ }^{2,25}$ Correct scrum setting and engagement techniques are extremely important, and if safe and effective techniques are sustained the scrum-related catastrophic cervical injury could be eliminated from the game. ${ }^{18}$

The crouch signal from the referee should see the front row forwards assuming a stationary crouched position. Although no research has related crouch position to force production in the scrum, a crouch position similar to the position of maximal force production while pushing is recommended. It is therefore recommended, for maximal force development as well as assurance of safety, that front-row players crouch with a low body position, a straight neutral spine (spine-in-line), face-up, and with their shoulders and hips at the same height. In the crouch position it is very important to emphasise a neutral cervical spine in natural lordosis. Players are therefore recommended to have their chin up and off their chests, but not hyperextended (tilted backward). Hyperextending in the crouch position will result in the need for flexion (bending the neck forward) in order to place the head under the opposite front-row. This act may place the front-row forward in a compromised position and increase the risk of catastrophic cervical injury. It is therefore recommended that players imagine they are looking at their opposite number in the crouch position over a pair on sunglasses placed on their nose.

The engage signal from the referee should be followed by both sets of front-row players driving into one another, ensuring that they maintain spine-in-line for optimal force transfer and personal safety. Research has shown that the magnitude of forward force generated by a pack of forwards once they have engaged is greater when the front row is packed as low as possible, ${ }^{23}$ with the head, trunk and legs in alignment, and ensuring a maximal angle at the hip. ${ }^{13} \mathrm{~A}$ practical evaluation of individual scrumming technique has shown that a horizontal spine is a strong predictor of scrumming performance. ${ }^{4}$ The hip angle has been shown to be a factor when building a model for predicting maximal pushing force in the scrum; the mean hip angle in this study was $123^{0} \pm 24^{0} .28$

The cervical, thoracic and lumbar spines are placed under a great amount of strain during the scrum engagement. Evidence suggests that the cervical spine, thoracic and lumbar spines are able to bear the greatest amount of axial forces when the spine is in a neutra position with natural lordosis (spine-in-line)..$^{10,21,26,27}$ The flexed and twisted spine was also less able to resist applied axial torques, thus a loss of the recommended spine-in-line may also increase the risk of torsional injury. ${ }^{21}$

The collapsed scrum also presents great risk of vertex impacts and forced hyperflexion with or without rotation when the heads of the front-row forwards, especially the hooker, strikes the ground. ${ }^{25,30}$ The most effective way of preventing scrum collapse is to ensure that there are no downward forces exerted on the engage. In a study of the kinetics of the scrum a downward force on all 3 front row players was recorded at all playing levels except for international frontrow forwards. ${ }^{23,24}$ This indicates poor technique in non-international front-row forwards. Maintenance of a flat straight neutral spine with natural lordosis (spine-in-line) will ensure maximal forward force transfer and no downward force generation.

\section{The lineout}

The propensity of the lineout to cause injury has recently been described as 'very low'. 6 It has the lowest incidence of injury when recorded as injury per player-hours and per event. ${ }^{1,6,17,18,25,33}$ Interestingly, lineouts have the highest severity (days off per injury) of any contact phase, ${ }^{6}$ and should therefore be an important consideration when assessing the risk factors for injuries. ${ }^{29}$ Cervical or lumbar spine facet joint injuries accounted for the majority of matchrelated contact injuries occurring during the lineout in professional rugby players. ${ }^{6}$ Although this study ${ }^{6}$ reported that only $7 \%$ of all lineouts were penalised, a similar number of events resulting in medical on-pitch attention occurred in both penalised and non-penalised lineouts.

The reported high frequency of cervical and lumbar facet injuries sustained in the lineout ${ }^{6}$ was in all probability the cause of jumpers losing their balance and falling, from their lifted position when jumping, to the ground. Preventing illegal actions (i.e. interfering with the opposite jumper or lifter to gain advantage) through stricter interpretation of the law and teaching the technique which offers the greatest stability to the jumping 'pod' (jumper and two supporters) may be effective ways of reducing lineout injuries.

For optimal force generation players lifting the jumper should assume a low body position with straight spine. An effective lifting technique, from a performance perspective, is also the safest. To ensure maximal height the front supporter should grip the legs of the jumper just above the knees. Stability from the front supporter may be increased by rotating the grip around the legs so that the two hands act as a clamp, keeping the legs of the lifter together while 
also preventing lateral movement and imbalance of the jumper. The back supporter should keep his hands open and place the thumbs under the bulge of the buttocks (i.e. in the subgluteal fold) with the fingers folding around the back and outside of the thigh. Both the grips described above will provide greater stability and a more efficient lifting position at full extension than the frequently used 'shorts grip'. After the ball has been caught the back lifter should close the space and move around slightly to protect the jumper from the opposition and prevent him from being interfered with. Supporters should be as close as possible to the jumper, as this ensures that the jumper reaches a maximal height, and also creates a stronger base of support. By decreasing the horizontal distance between the supporters and the jumper, supporters decrease the resistive torque exerted by the jumper, and will therefore experience less force on their bodies. ${ }^{11}$ It is important that the jumper produces maximal power when initiating the jump. To ensure maximal power generation a counter-movement jump (i.e. bending the knees before the jump) should precede a maximal effort jump.

Once the jumper has captured the ball, the supporters should lower the lifter with controlled motion; dropping or letting go of the jumper might cause severe injury. The jumper should always maintain a straight body position, avoiding any flexion at the hip or knee joints, and should also ensure that a contracted core is maintained.

Although the specific lifting techniques mentioned above and their ability to create a safer and more effective lift have not been studied systematically, it may be argued that the techniques are supported by biomechanical principles. ${ }^{34}$

\section{The ruck and maul}

The tendencies of sustaining ruck and maul injuries have recently been classified as low and average, respectively. ${ }^{6}$ The number of ruck and maul injuries sustained per 1000 events was lower than the equivalent measure in the tackle and in the scrum. ${ }^{6}$ Haematoma injuries of the calf or shin caused the highest incidence and most days absent respectively for the forwards and backs during rucks, and medial collateral ligament injuries were the most common serious injuries associated with mauls. ${ }^{1}$ A case review study has shown that the ruck and maul causes $17 \%$ of all catastrophic cervical spine injuries. ${ }^{30}$ There are various possible mechanisms for catastrophic cervical injury. ${ }^{25,30}$ Firstly, the ruck and maul situation might lead to forced flexion of the neck, either to the ball-carrier or a player at the bottom of a ruck. Secondly, head and neck injuries may result from vertex impacts caused by charging into a mass of players, either to the person charging and making head-first contact or to the person bearing the force of the contact. ${ }^{25,30}$ Thirdly, fracture and dislocation may occur from vertex impacts or forced hyperflexion and rotation similar to the mechanism described in the other contact phases of the game. 25,30

Players joining the ruck, which is formed once 'one or more players from each team, who are on their feet, in physical contact, close around the ball on the ground, ${ }^{15}$ should according to law 16 , 'have their head and shoulders no lower than the hips'. A strong effective technique with straight neutral spine in natural lordosis, face-up, shoulders above the hips and strong base of support will assist the necessary force production to clear opposition players off the ball and provide stability to stay on the feet, thus ensuring fast and effec- tive ball availability for the scrumhalf. A straight neutral lumbar, thoracic and cervical spine is recommended due to the increased stability of the spine in this position. ${ }^{11,21,26,27}$ The strongest position of the spine is essential in force production and injury prevention. Although players should be coached not to charge into rucks head-first, the risk of vertex impacts around the ruck situation should always be reduced by keeping the face up; this avoids the risk of vertex impacts with a forward flexed cervical spine, which has been shown to be a very vulnerable position. ${ }^{10,26}$ The above recommendations apply to defending players entering the ruck situation and attacking players securing the ball. Players going off their feet or entering the ruck with their shoulders below the hips will not only be less effective at driving opposition players off the ball, but will also be penalised because this is also a transgression of the law of the game.

The fundamental difference between the ruck and a maul is that 'all players involved must be caught in or bound to the maul and must be on their feet'. ${ }^{15}$ The above-mentioned principles of safe position in the ruck situation thus also apply to the maul. In the maul situation, the ball-carrier who remains on his feet is also at risk when he remains facing his opposition with his head down. ${ }^{25}$ Players should be encouraged to turn their back towards the opposition when held in a tackle as this action will enhance ball retention rate ${ }^{22,37}$ and increase the safety factor when the maul is formed. This example once again demonstrates that safe rugby is effective rugby.

\section{Acknowledgements}

The paper was commissioned by the BokSmart programme, which is a national programme sponsored by ABSA and implemented on behalf of the South African Rugby Union and the Chris Burger/Petro Jackson Player's Fund. The goal of the programme is to teach safe and effective techniques which will reduce the incidence and severity of injury, make the game safer for all involved and improve rugby performance.

\section{REFERENCES}

1. Brooks JHM, Kemp SPT. Recent trends in rugby union injuries. Clin Sports Med 2008; 27: 51-73.

2. Brooks JHM, Fuller CW, Kemp SPT, Reddin DB. Epidemiology of injuries in English professional rugby union: part 1 match injuries. $\mathrm{Br} J$ Sports Med 2005; 39(10):757-66.

3. Clark DR, Roux C, Noakes TD. A prospective study of the incidence and nature of injuries to adult rugby players. S Afr Med J 1990; 77: 559-62.

4. Coaches Information Website. Assessment of Scrumming Performance. Available at: http://cis.myile.com/index.php. Accessed 26 May 2008

5. Fuller CW, Molley MG, Bagate C, et al. Consensus statement of injury definitions and data collection procedures for studies of injuries in rugby union. Br J Sports Med 2007; 41: 328-31.

6. Fuller CW, Brooks JHM, Cancea RJ, Hall J, Kemp SPT. Contact events in rugby union and their propensity to cause injury. Br J Sports Med 2007; 41: 862-7.

7. Fuller CW. Managing the risk of injury. Clin J Sport Med 2007; 17(3): $182-7$

8. Gabbett TJ. Influence of fatigue on tackling technique in rugby league players. J Strength Cond Res 2008; 22(2):625-32.

9. Garraway WM, Lee, AJ, MacLeod DA, Telfer JW, Deary IJ, Murray GD. Factors influencing tackle injuries in rugby union football. Br J Sports Med 1999; 33: 37-41

10. Gunning JL, Callaghan JP, McGill SM. Spinal posture and prior loading history modulate compressive strength and type of failure in the spine: a biomechanical study using a porcupine cervical spine model. Clin Biomech 2001; 16(6): 471-80.

11. Harman E. The biomechanics of resistance exercise. In: Beachle TR, Earle RW II, eds. Essentials of Strength and Conditioning. Champaign, IL: Human Kinetics, 2000: 25-55.

12. Heck JF, Clarke KS, Peterson TR, Torg JS, Weis MP. National athletics trainers' association position statement: head-down contact and spearing in tackle football. J Athletic Training 2004; 39(1): 101-11. 
13. Hodge KP. Spinal injuries in rugby scrums. Res Papers Physical Edu 1980; 2(4): 82.

14. International Rugby Board (IRB). About IRB organisation. Available at: http://www.irb.com/aboutirb/organisation/index.html. Accessed 2 June 2008.

15. International Rugby Board (IRB). IRB Playing charter (IRB rugby rules) 2008 edition. Available at: http://www.irb.com/mm/Document/LawsRegs/0/COMPLETELAWS 4809.pdf. Accessed 2 June 2008.

16. Jones NMP, Mellalieu SD, James N, Moise J. Contact area playing styles of northern and southern hemisphere international rugby union teams. In: O'Donoghue P, Hughes P. Performance Analysis of Sport VI. Cardiff: In: O'Donoghue P, Hur
UWIC, 2005: 114-9.

17. Kerr HA, Curtis CM, Micheli LJ, et al. Collegiate rugby union injury patterns in New England: A prospective cohort study. Br J Sports Med 2008; 42(7): 595-603

18. Kew T, Noakes TD, Kettles AN, Goedecke RE, Newton DA, Scher AT. A retrospective study of spinal cord injuries in Cape Province rugby players, 1963 -1989. S Afr Med J 1991; 80:127-33.

19. Macintosh AS, McCrory P. Preventing head and neck injuries. Br J Sports Med 2005; 39: 314-8.

20. Macintosh AS, McCrory P, Finch CF, Wolfe R. Head, face and neck injury in youth rugby: incidence and risk factors. Br J Sports Med 2008. Doi: 10.1136/bjsm.2007.041400.

21. McGill SM. The influence of lordosis on axial trunk torque and trunk muscle myoelectric activity. Spine 1992; 17(10): 1187-93.

22. McKenzie AD, Holmyard DJ, Docherty D. Quantitative analysis of rugby: factors associated with success in contact. J Human Movement Studies 1989; 17: 101-13.

23. Millburn PD. The kinetics of rugby union scrummaging. J Sports Sci 1980 8: $47-60$.

24. Millburn PD. Biomechanics of rugby union scrumming. Sports Med 1993; 16(3):168-79.

25. Noakes TD, Du Plesssis M. Rugby Without Risk: A Practical Guide to the Prevention and Treatment of Rugby Injuries. Pretoria: Van Schaik, 1996.

26. Oktenoglu T, Ozer AF, Ferrara LA. Effects of cervical spine posture and axial load bearing ability: a biomechanical study. J Neurosurg 2001; 94(1 Suppl.): 108-14.
27. Patwardhan AG, Havey RM, Ghanayem AJ, et al. Load-carrying capacity of the human cervical spine in compression is increased under a follower load. Spine 2000; 25(12): 1548-54.

28. Quarrie KL, Wilson BD. Force production in the rugby union scrum J Sports Sci 2000; 18: 237-46.

29. Quarrie KL, Alsop JC, Waller AE, Bird YN, Marshall SW, Chalmers DJ. The New Zealand rugby injury and performance project. VI. A prospective cohort study of risk factors for injury in rugby union football. $\mathrm{Br} J$ Sports Med 2001; 35:157-66.

30. Quarrie KL, Cantu C, Chalmers DJ. Rugby union injuries to the cervical spine and spinal cord. Sports Med 2002; 32(10): 633-53.

31. Quarrie KL, Gianotti S, Hopkins WG, Hume PA. Effect of a nationwide injury prevention programme on serious spinal injuries in New Zealand rugby union: ecological study. Br Med J 2008; 334(7604): 1150.

32. Quarrie KL, Hopkins WG. Tackle injuries in professional rugby union. Am J Sports Med 2008. DOI: 10.1177/0363546508316768.

33. Roux CE, Goedecke R, Visser GR, Van ZyI WA, Noakes TD. The epidemiology of schoolboy rugby injuries. S Afr Med J 1987; 71: 307-13.

34. Sanders RH, Wilson BD. Some biomechanical tips for better teaching and coaching. N Z J Health Phys Edu Recreation 1991; 23(3): 24(1\&2)

35. Sayers MGL, Washington-King J. Characteristics of effective ball carries in Super 12 rugby. Int J Performance Analysis Sport 2005; 5(3): 92-106.

36. Silver JR. The impact of the 21 st century on rugby injuries. Spinal Cord 2002; 40: 552-9.

37. Smyth G, O'Donoghue PG, Wallace ES. Notational analysis of contact situations in rugby union. In: Hughes MD, ed. Notational Analysis of Sport IV. Cardiff: UWIC, 1998:156-64.

38. South African Rugby Union. Community rugby department statistics. Personal communication. 28 May 2008.

39. Torg JS, Quedenfeld TC, Moyer RA, Truex R, Speelman AD, Nichols CE. Severe and catastrophic neck injuries resulting from tackle football. $J \mathrm{Am}$ Coll Health Assoc 1977; 25: 224-6.

40. Wetzler MJ, Akpata T, Laughlin W, Levy AS. Occurrence of the cervical spine injuries during the rugby scrum. Am J Sports Med 1998; 26(2): $177-80$

41. Wilson BD, Quarrie KL, Millburn PD, Chalmers DJ. The nature and circumstances of tackle injuries in rugby union. J Sci Med Sport 1999;

\section{UNIVERSITY OF THE WESTERN CAPE}

\section{ASSOCIATE PROFESSOR/PROFESSOR IN SPORT, RECREATION AND EXERCISE SCIENCE}

The Department of Sport, Recreation and Exercise Sciences at UWC has great potential to become a leader in promoting and developing communities through sport and other forms of physical activity. It is unique in that it offers a postgraduate qualification in sport and recreation management, as well as an opportunity for students to specialise in this discipline at the undergraduate level. In addition, it educates students in biokinetics and has well-established undergraduate and postgraduate programmes in the fields of sport, recreation and exercise science. The Department has substantive international links with tertiary institutions offering opportunities for collaborative research and teaching. Discussions with international colleagues to establish a sports research centre at UWC are underway.

The Department has a vacancy for an associate professor/professor with effect from 1 January 2009. The prime duty of any professor is to give advanced academic leadership. As in all academic appointments, the position entails administrative, research, research supervision, teaching and community outreach responsibilities. The successful candidate should possess the following:

1. A relevant doctoral degree

2. A significant research track record in any of the exercise sciences

3. High-quality, peer-reviewed publications;

4. A track record of successful postgraduate supervision;

5. Experience in teaching at a tertiary institution in undergraduate and postgraduate programmes; and

6. An understanding of the demands and needs of relevant markets for which sport, recreation and exercise science students are being prepared.

The successful candidate must be willing to facilitate the establishment of a sports research centre and to work in interdisciplinary teams. In addition, the candidate would be expected to stimulate and co-ordinate research, attract project funding, and develop strategic research plans.

Your application should highlight your strengths as an educator and researcher in the exercise science area and should be accompanied by a full curriculum vitae and the names and full contact particulars, i.e. e-mail addresses, telephone and cell numbers and postal addresses of three referees. Further information may be obtained from Dr S Bassett on telephone (021 9592350) or e-mail: sbassett@uwc.ac.za. The closing date is 24 October 2009.

Applications should be addressed to: Ms G Alexander e-mail: galexander@uwc.ac.za, or at Human Resources Department, University of the Western Cape, Private Bag X17, Bellville 7535, South Africa. Tel: +27-21-9593626. Fax: +27-21-959-1447

In line with the University's commitment to diversifying its workforce, applications from the designated groups will be given priority consideration. The University reserves the right not to make an appointment or to make an appointment at a lower level. We will only correspond with short-listed candidates. 